\title{
AVALIAÇÃO DA QUALIDADE DOS SERVIÇOS DO SETOR FINANCEIRO DE UMA UNIVERSIDADE: UMA ANÁLISE COMPARATIVA ENTRE A VISÃO DOS SERVIDORES PRESTADORES E DOS SERVIDORES USUÁRIOS DOS SERVIÇOS
}

\author{
SERVICES QUALITY ASSESSMENT OF FINANCIAL SECTOR OF A UNIVERSITY: A COMPARATIVE ANALYSIS OF \\ VISION OF SERVERS PROVIDERS AND SERVERS USERS OF SERVICES
}

Silvana Dalmaso Tolfo', Henrique Schneider Roth ${ }^{2}$, Vanessa Abreu Dias ${ }^{3}$, Gustavo de Carvalho Luiz ${ }^{4}$

RECEBIDO EM: 23/11/2016 / APROVADO EM: 21/12/2016

DOI: $10.5902 / 2317175824825$

\begin{abstract}
RESUMO
Este estudo versa sobre a avaliação da qualidade dos serviços prestados no setor financeiro da Universidade Federal do Pampa (UNIPAMPA), a fim de efetuar uma comparação entre a percepção dos servidores lotados no setor e a visão dos servidores usuários dos serviços. Para tanto, o modelo utilizado foi baseado na SERVPERF adaptado para quatro dimensões, e a pesquisa foi composta de duas fases: uma entrevista com quatro servidores do setor financeiro e um questionário enviado para os servidores docentes e técnicos administrativos usuários dos serviços do setor, obtendo-se 140 respostas válidas. Analisando os resultados, verificou-se que os serviços prestados no setor financeiro da instituição contam com uma boa avaliação por parte dos seus usuários, sendo a discordância entre as percepções de servidores prestadores dos serviços e de usuários limitada a alguns pontos específicos.
\end{abstract}

Palavras-chave: Qualidade dos serviços; Setor financeiro; Avaliação.

\footnotetext{
1 Possui graduação em Ciências Contábeis pela Universidade da Região da Campanha. Especialização em Gestão de Organizações Bancárias pela UFSM, Mestranda do Programa de Mestrado Profissional em Gestão de Organizações Públicas da UFSM. Atualmente é contadora na Universidade Federal do Pampa. 2 Possui graduação em Administração pela Universidade Federal de Santa Maria. Mestrando no Programa de Mestrado Profissional em Gestão de Organizações Públicas da Universidade Federal de Santa Maria.

3 Possui graduação em Biblioteconomia pela Universidade Federal do Rio Grande (2005). Mestranda no curso de Mestrado em Gestão de Organizações Públicas da UFSM.

4 Possui graduação em Administração pela Universidade da Região da Campanha (2007) e Especialização em Gestão Pública pela Universidade Federal do Rio Grande do Sul (UFRGS). Atualmente é Mestrando do Mestrado Profissional em Gestão de Organizações Públicas da Universidade Federal de Santa Maria (UFSM).
} 
AVALIAÇ̃̃O DA QUALIDADE DOS SERVIÇOS DO SETOR FINANCEIRO DE UMA UNIVERSIDADE: UMA ANÁLISE COMPARATIVA ENTRE A VISÃO DOS SERVIDORES PRESTADORES E DOS SERVIDORES USUÁRIOS DOS SERVIÇOS

\begin{abstract}
The versa study on the evaluation of the quality of services in the financial sector of the Universidade Federal do Pampa, where we tried to make a comparison between the perception of the crowded servers in the industry with the vision of the server service users. Thus, the model used was based on SERVPERF adapted to four dimensions and research consisted of two phases: an interview with four servers of the financial sector and a questionnaire sent to teachers and technical servers administrative users of the services sector, which it obtained 140 valid responses. Analyzing the results, it was found that the services provided in the financial sector of the institution climbed a good evaluation by the users of the services, and the discrepancy between the perceptions of providers of services servers and users have been limited to a few specific points.
\end{abstract}

Keywords: Quality of services; Financial sector; Assessment.

\title{
1 Configurando um ecossistema comunicacional pelo Pensamento Complexo
}

O tema da qualidade dos serviços ganhou importância na década de 1980, quando as organizações passaram a buscar a excelência nos serviços e a ver o cliente como peça-chave para conquista e manutenção dos mercados (Freitas, 2005). De acordo com Albrecht (1992, p. 254), a qualidade na prestação dos serviços oferecido "é a capacidade que uma experiência ou qualquer outro fator tenha para satisfazer uma necessidade, resolver um problema ou fornecer benefícios a alguém". Entende-se, assim, que um serviço de qualidade é aquele capaz de gerar satisfação ao seu cliente, o que é vital para o sucesso de uma organização.

Para Soares (1994, p. 14), "qualidade em serviços significa atender as reais necessidades dos clientes, sejam elas explícitas ou implícitas dentro do prazo que o cliente deseja e a um justo valor". Já Las Casas (1995, p. 187) define "serviço de qualidade como sendo aquele em que o cliente fica satisfeito com os resultados obtidos, de acordo com suas expectativas".

As definições de qualidade na prestação de serviços demonstram que as expectativas do usuário é que irão levá-lo a ter um sentimento de satisfação com o serviço oferecido: se a experiência se igualar ou for superior às expectativas, haverá satisfação por parte do cliente; caso o serviço for inferior, haverá insatisfação.

Tendo isso em vista, no decorrer deste trabalho, buscou-se fazer uma análise acerca do tema da qualidade de serviços, bem como das dimensões conhecidas para a formação de tais conceitos: confiabilidade, presteza, 
empatia e segurança. Nesse sentido, a pesquisa teve como finalidade realizar uma avaliação da qualidade dos serviços prestados pela Coordenadoria de Contabilidade e Finanças da Universidade Federal do Pampa (UNIPAMPA) na percepção dos servidores usuários desses serviços e compará-la com a concepção dos servidores do setor. O estudo buscou, ainda, trazer contribuições ao setor financeiro da instituição, assim como benefícios para a sociedade como um todo, uma vez que os resultados obtidos podem servir para melhoria e qualificação contínua dos processos do setor.

\section{Revisão da literatura}

Neste tópico, são abordados os conceitos relacionados ao marketing de serviços e à qualidade em serviços.

\subsection{Marketing de serviços}

O conceito de serviço está relacionado à atividade que envolve o fornecimento de soluções para questões apresentadas pelo público consumidor. Nesse entendimento, Grönroos (2004, p. 65) define o serviço como

um processo, consistindo em uma série de atividades mais ou menos intangíveis que, normalmente, mas não necessariamente sempre, ocorrem nas interações entre o cliente e os funcionários de serviços e/ou bens físicos e/ou sistemas do fornecimento de serviços e que são fornecidas como soluções para problemas do cliente.

Conforme Luiz (2014, p. 1), o serviço é o "conjunto de atividades realizadas por uma empresa para responder às expectativas e necessidades do cliente". O conceito de serviços relaciona-se com a prática do marketing em organizações. Nas últimas décadas, vem ocorrendo um aumento exponencial nas pesquisas relacionadas ao marketing de serviços, o que é fruto da expansão econômica e do contexto mundial que permite a aproximação de mercados.

De acordo com Nascimento (2012, p. 43),

A expansão dos mercados regionais e mundiais levou à necessidade de produzir conhecimentos científicos sobre vendas e consumo, tornando relevante a análise objetiva dos elementos determinantes da eficiência e eficácia desses diferentes segmentos de mercado.

Mota (2009, p. 7) destaca que os estudos sobre marketing de serviços relacionam-se aos conceitos de intangibilidade, heterogeneidade, simultaneidade e inseparabilidade, estabelecendo uma nova visão estratégica para a gerência das práticas de marketing. Conforme Nascimento (2012, p. 46), o conceito de intangibilidade traduz-se "pela falta de percepção concreta 
AVALIAÇÃO DA QUALIDADE DOS SERVIÇOS DO SETOR FINANCEIRO DE UMA UNIVERSIDADE: UMA ANÁLISE COMPARATIVA ENTRE A VISÃO DOS SERVIDORES PRESTADORES E DOS SERVIDORES USUÁRIOS DOS SERVIÇOS

que a empresa prestadora de serviços promove à sua clientela. Um serviço é de domínio intangível, formado por atividades imateriais [...] e dificilmente observáveis por pessoas externas". Na visão de Kotler (2006), a intangibilidade existe porque os serviços não são palpáveis, mas são como ideias e conceitos, de modo que a reputação de quem presta o serviço é que norteará o consumidor. Isso quer dizer que o cliente, no momento em que se depara com o fornecedor, não tem a real percepção sobre a qualidade do serviço, a não ser por experiências anteriores ou recomendações de terceiros.

O conceito relacionado à heterogeneidade envolve a pluralidade de abordagens vinculadas aos seres humanos nas relações de serviços. Nesse sentido, de acordo com Mota (2009, p. 31), a “heterogeneidade está principalmente relacionada ao fato dos serviços terem envolvidos na sua realização seres humanos, que por constituição são diferentes uns dos outros, acarretando, portanto, diferenças de qualidade na entrega de um serviço".

Com a mesma visão, Nascimento $(2012$, p. 48) destaca que:

Em um primeiro momento, não podemos afirmar que todo o pessoal da empresa que estabelece um contato com o cliente possua o mesmo nível de competência técnica ou interpessoal nem que um indivíduo possa estar disposto a fornecer regularmente e com a mesma continuidade o mesmo desempenho.

Sobre a dimensão da simultaneidade, que está presente nas características do marketing de serviços, Coutinho e Misunaga (2011, p. 10) visualizam esse conceito no fato de o serviço ser realizado e consumido ao mesmo tempo.

Quanto à característica da inseparabilidade, deve existir uma ligação entre o prestador de serviço e o cliente. Diante disso, Oliveira et al. (2009, p. 3) destacam que

A inseparabilidade está associada ao fato de que a produção de um serviço não pode ser separada de seu consumo pelo cliente. Diferentemente de bens físicos que são produzidos, estocados e distribuídos, os serviços não podem ser guardados. A perecebilidade acontece porque a capacidade de serviço que não é utilizada num determinado período de tempo não pode ser estocada para uso futuro. Porém, diferentemente de bens, que são menos sensíveis à perecebilidade, os serviços podem ser planejados de acordo com a flutuação da demanda.

Com essa mesma linha de pensamento, Nascimento $(2012$, p. 49) entende que a inseparabilidade é um modelo que

[...] ilustra a dinâmica que liga o cliente ao prestador de serviços. Essa atividade conjunta torna-se, pela força da prática, interativa e recíproca. Doravante o que distingue uma organização de outra, é a compreensão da responsabilidade que o pessoal diretamente em contato com o cliente assume e o mecanismo dessa interação única. 
Essas características fazem parte do conceito do marketing de serviços, que está cada vez mais presente nas pesquisas relacionadas às relações entre os prestadores de serviços e os clientes finais.

\subsection{Qualidade em serviços}

A procura dos consumidores está cada vez mais direcionada a serviços que ofereçam um custo-benefício aliado à qualidade, motivo pelo qual a qualidade é um fator de grande importância para os clientes.

Nesse enfoque, de acordo com Luiz (2014, p. 2),

Uma vez alinhado o entendimento conceitual sobre serviço, podemos definir a Qualidade em Serviços como o grau em que as expectativas dos clientes são atendidas, por meio de mecanismos que favoreçam a identificação de suas necessidades e possibilitem a percepção sobre o serviço prestado.

Parasuraman, Zeithaml e Berry (1988) definem o conceito de qualidade de serviço de acordo com cinco dimensões: confiabilidade, presteza, cortesia, empatia e tangibilidade. Segundo Bateson e Hoffman (2001), a confiabilidade é a capacidade de realizar o serviço prometido de forma confiável e precisa.

Corrêa (2000, p. 1), por sua vez, conceitua a confiabilidade como

O primeiro fator na determinação da qualidade de serviços [...]. Este fator determina a credibilidade obtida pela empresa no processo de interação com o cliente. Para que o cliente perceba a credibilidade e a empresa possa obter vantagem em relação a este fator, a empresa deve dar atenção na hora de desenvolver novos produtos ou serviços (ou mesmo analisando os já existentes), de apenas prometer e comunicar para o cliente as características as quais ele possa entregar, dentro dos termos também acertados entre as partes.

Quanto ao conceito da presteza, de acordo com Machado et al. (2006, p. 4), o termo refere-se "à vontade de ajudar o consumidor a prover o prontoserviço". Já a dimensão de cortesia, segundo Araújo et al. (2011, p. 5), envolve o conhecimento, a maneira e a habilidade dos funcionários para comunicar confiança e segurança aos clientes.

Com relação à empatia, esta é uma dimensão muito apreciada pelos consumidores, que, conforme Moura et al. (2007, p. 4), corresponde à atenção individualizada que as empresas proporcionam a seus clientes. Las Casas (1999) afirma que a empatia consiste no grau de cuidado e atenção pessoal dispensado aos clientes, como a capacidade de se colocar no lugar dos outros, e na receptividade, que é a disposição de ajudar os clientes.

Costa (2009, p. 11) define a tangibilidade como a dimensão que diz respeito essencialmente à aparência, tanto do ambiente, das instalações e 
AVALIAÇ̃̃O DA QUALIDADE DOS SERVIÇOS DO SETOR FINANCEIRO DE UMA UNIVERSIDADE: UMA ANÁLISE COMPARATIVA ENTRE A VISÃO DOS SERVIDORES PRESTADORES E DOS SERVIDORES USUÁRIOS DOS SERVIÇOS

dos equipamentos quanto do pessoal. Kotler (1998) possui a mesma visão, mencionando que a tangibilidade representa a aparência das instalações físicas, dos equipamentos, dos funcionários e dos materiais de comunicação.

Em suma, o marketing de serviços e a qualidade em serviços são conceitos que permeiam as relações entre os fornecedores e os clientes, e o aprimoramento dessas dimensões tende a resultar em uma equação que beneficia toda a cadeia de mercado, de forma integrada, em todas as fases dos processos.

De acordo com Oliver (2010 apud Milan et al., 2013), a

\begin{abstract}
Qualidade percebida de um serviço pode ser entendida como um conceito relativo a como um determinado serviço se desenvolve, enquanto que a satisfação do cliente é vista como um conceito direcionado à avaliação de quão bem sucedido tal serviço foi realizado no que se refere ao preenchimento das expectativas dos clientes em relação às suas necessidades e seus desejos.
\end{abstract}

Nesse sentido, a qualidade é um construto anterior à satisfação do cliente, ou seja, a qualidade resulta do desempenho percebido pelo cliente em relação às suas expectativas, surgindo ao longo da prestação do serviço. Já a satisfação tem uma amplitude maior, pois está baseada, também, em necessidades e em experiências anteriores (Milan et al., 2013).

Também compartilham dessa ideia Salomi et al. (2005, p. 283), os quais relatam: "Cronin e Taylor (1992) afirmaram ainda, que a qualidade percebida dos serviços é um antecedente à satisfação do cliente, e que essa satisfação tem efeito significativo nas intenções de compra". Segundo Tontini e Sant'Ana (2008), atender às necessidades dos clientes é fundamental para sua satisfação e para promover o êxito da instituição em longo prazo, já que clientes satisfeitos tendem a consumir novamente na organização e são menos suscetíveis a importarem-se com os preços.

Com relação à avaliação da qualidade em serviços, Parassuraman et al. (1988) desenvolveram uma ferramenta denominada Service Quality, conhecida como SERVQUAL. O instrumento destina-se a efetuar a avaliação da qualidade em serviços, baseando-se em cinco dimensões, tangibilidade, confiabilidade, compreensão, segurança e empatia, por meio de uma comparação entre a percepção do "ideal" e do "real", permitindo encontrar os "gaps" de qualidade, ou seja, a diferença entre a expectativa e o que realmente é percebido pelo cliente.

O gap, ou diferença entre a expectativa e o desempenho, é uma medida da qualidade do serviço em relação a uma característica específica. Os critérios chamados de dimensões da qualidade, determinados por Parasuraman et al. (1985), são características genéricas do serviço, subdivididas em itens, que delineiam serviço sob o ponto de vista do cliente que irá julgá-lo (Salomi et al., 2005, p.280-281). 
Mais tarde, em 1992, Cronin e Taylor, criaram a escala SERVPERF, a qual é baseada somente na percepção do desempenho dos serviços, sem medir a expectativa dos clientes. Esse instrumento utiliza as mesmas dimensões de qualidade da SERVQUAL propostas por Parassuraman et al. (1988), mas emprega apenas a metade das questões, sendo composto, assim, de 22 itens.

Para justificar seu modelo, Cronin e Taylor (1992) ressaltam que a qualidade é conceituada mais como uma atitude do cliente com relação às dimensões da qualidade, e que não deve ser medida com base no modelo de satisfação de Oliver (1980), ou seja, não deve ser medida por meio das diferenças entre expectativa e desempenho, e sim como uma percepção de desempenho (Salomi et al., 2005, p. 283).

\section{Método de pesquisa}

A UNIPAMPA é uma instituição pública de ensino superior com estrutura multicampi, a qual está estabelecida em dez municípios situados da metade sul do Rio Grande do Sul. A Coordenadoria de Contabilidade e Finanças (CCF) da Universidade é um setor que faz parte da Pró-Reitoria de Administração (PROAD), a qual é composta atualmente 13 servidores, que ocupam os cargos de Contador, Técnico em Contabilidade, Administrador e Assistentes em Administração.

A Coordenação é organizada em duas divisões: Divisão de Contabilidade e Divisão de Finanças. A primeira possui relação direta com as seções de análises e regularizações contábeis, retificação de receita pública e folha de pagamento e com o setor de empenho pelo Sistema de Administração Financeira do Governo Federal (SIAFI). A segunda abrange os setores de diárias e passagens, suprimento de fundos, importações, liquidação e pagamento de despesa, bem como o controle financeiro de contratos.

Devido ao fato de a CCF centralizar a Contabilidade e Finanças de toda a Universidade, o setor possui comunicação direta com a Reitoria e os dez campi da instituição, bem como com fornecedores e outros sujeitos envolvidos nos processos de rotina do setor. Por essa razão, o setor realiza, diariamente, interlocuções operacionais com os mais diferentes usuários, tornando-se uma engrenagem fundamental para o funcionamento da instituição.

Para atender o objetivo do trabalho, utilizou-se uma triangulação por meio de uma pesquisa qualiquantitativa descritiva. Segundo Gil (2012, p. 28), as pesquisas descritivas "têm como objetivo primordial a descrição das características de determinada população ou fenômeno ou o estabelecimento de relações entre variáveis". De acordo com o autor, o estudo de determinadas particularidades ou atitudes de um grupo caracteriza uma pesquisa do tipo descritiva.

Conforme Andrade (2005), na pesquisa descritiva, os fatos são estudados e analisados pelo pesquisador, sem que haja, contudo, a sua interferência. 
AVALIAÇ̃̃O DA QUALIDADE DOS SERVIÇOS DO SETOR FINANCEIRO DE UMA UNIVERSIDADE: UMA ANÁLISE COMPARATIVA ENTRE A VISÃO DOS SERVIDORES PRESTADORES E DOS SERVIDORES USUÁRIOS DOS SERVIÇOS

Além disso, uma característica desse tipo de pesquisa consiste na técnica padronizada da coleta de dados, geralmente realizada via questionários e observação sistemática.

De acordo com Gil (2012), na pesquisa qualitativa, existe uma relação dinâmica entre o mundo real e o sujeito, isto é, um vínculo indissociável entre o mundo objetivo e a subjetividade do sujeito que não pode ser traduzido em números, de modo que a interpretação dos fenômenos e a atribuição de significados são necessárias nesse tipo de pesquisa. Já a pesquisa quantitativa é aquela em que os dados podem ser classificados e analisados por meio de ferramentas estatísticas.

\subsection{População e amostra}

Na etapa quantitativa, foram pesquisados os servidores da UNIPAMPA lotados nos dez campi e na Reitoria. O quadro de pessoal da instituição, atualmente, é formado 819 docentes e 838 técnicos-administrativos, totalizando 1.657 servidores. A amostra foi do tipo probabilística simples, considerando um nível de confiança de $95 \%$ e um erro amostral de $8 \%$ e sendo formada por 140 questionários válidos.

No que diz respeito à etapa qualitativa, foram entrevistados quatro servidores do setor financeiro da instituição, os quais ocupam os cargos de Contador, Técnico em Contabilidade, Administrador e Assistente em Administração - um deles possui cargo de chefia. A idade dos servidores é de $30,33,25$ e 36 anos, respectivamente, e o tempo de serviço desses servidores na instituição varia entre dois e cinco anos.

\subsection{Procedimentos de coleta de dados}

$\mathrm{Na}$ etapa quantitativa, o instrumento de pesquisa foi composto de 29 questões, divididas em três seções: a primeira contém sete perguntas referentes ao perfil do servidor e à sua unidade de lotação; a segunda possui 17 questões que buscam verificar a qualidade dos serviços da CCF, com base no modelo SERVPERF, proposto por Cronin e Taylor (1992), o qual foi adaptado para uma escala tipo likert de 5 pontos; e a terceira possui quatro tópicos com variáveis antagônicas (GUPTA, 2010), que têm como objetivo a avaliação do grau de satisfação com relação aos serviços prestados pela Coordenadoria.

A coleta de dados ocorreu mediante o envio de um questionário por meio da ferramenta Google Docs, em que foi elaborado e disponibilizado um formulário eletrônico na forma de questionário a todos os servidores dos dez campi e da Reitoria da instituição pesquisada no período de 08 a 17 de junho de 2016. Em seguida, os questionários utilizados na etapa quantitativa foram adaptados para uma entrevista semiestruturada, mantendo as mesmas dimensões do modelo SERVPERF (confiabilidade, presteza, segurança e empatia), a qual foi realizada no período de 27 a 29 de junho de 2016. 


\subsection{Tratamento e análise dos dados}

A ferramenta utilizada para o cruzamento dos dados estatísticos foi o software Statistical Package for Social Science (SPSS), que permitiu analisar o perfil dos respondentes, efetuando as análises descritivas (média e desviopadrão) e verificando a influência do perfil nas dimensões do modelo.

A análise qualitativa foi feita com base na análise de conteúdo. Segundo Campos (2004, p. 612), "Bardin configura a análise de conteúdo como um conjunto de técnicas de análise das comunicações, que utiliza procedimentos sistemáticos e objetivos de descrição do conteúdo das mensagens".

De acordo com os pressupostos de Bardin (2009), a análise de conteúdo não deve ser revestida de um texto extremamente formal e objetivo, a fim de não afetar a criatividade e capacidade intuitiva do pesquisador, ao mesmo tempo que não deve ser tão subjetiva, de forma a não consistir apenas em um mero confirmador de suas próprias ideias.

\section{Apresentação e discussão dos resultados}

Para facilitar o entendimento deste estudo, a apresentação dos resultados está dividida em dois tópicos: a análise da entrevista com os servidores do setor financeiro da instituição e a avaliação da pesquisa com os servidores usuários.

4.1 Análise da entrevista com os servidores lotados no setor financeiro

A ferramenta SERVQUAL (Parasuraman et al., 1988), que deu origem ao modelo SERVPERF (Cronin e Taylor, 1992 apud Salomi, 2004) é composta de cinco dimensões, conhecidas como dimensões da qualidade. Os resultados encontrados na pesquisa estão organizados de acordo com cada uma dessas dimensões.

Os trechos de respostas dos entrevistados, listados a seguir, retratam uma opinião homogênea com relação à dimensão "confiabilidade", que se refere à habilidade da empresa em prestar o serviço corretamente e dentro do prazo acordado. Quando perguntados a esse respeito, os servidores responderam: "[...] com certeza o setor financeiro procura sempre cumprir os prazos, salvo raras exceções [...]" (entrevistado 2), "Nós fazemos o possível para atender todas as demandas dentro do prazo estipulado, há um esforço em equipe para que isso aconteça" (entrevistado 2) e "Sempre que possível cumprimos, nos empenhamos para cumprir e responder as solicitações com a maior brevidade possível [...]" (entrevistado 4).

Já no que concerne aos procedimentos rotineiros, os entrevistados relataram: "Cada um tem as suas rotinas específicas, mas, mesmo na falta de um colega, nós sempre procuramos resolver o problema" (entrevistado 1), "Nosso setor é muito organizado, nós temos um padrão que todos seguem [...]" (entrevistado 3), 
AVALIAÇÃO DA QUALIDADE DOS SERVIÇOS DO SETOR FINANCEIRO DE UMA UNIVERSIDADE: UMA ANÁLISE COMPARATIVA ENTRE A VISÃO DOS SERVIDORES PRESTADORES E DOS SERVIDORES USUÁRIOS DOS SERVIÇOS

"Temos os processos muito bem desenhados aqui na CCF. Cada um sabe o papel que desempenha na engrenagem [...]" (entrevistado 4) e "[...] de acordo com a lei, com os procedimentos que já estão preestabelecidos [...]" (entrevistado 2).

Com relação à resolução de problemas, os entrevistados afirmam que: "A resolução sempre é dada embasada nas leis [...]" (entrevistado 1), "A resolução dos problemas também passa pelo trabalho em equipe, cada um contribui dentro dos seus conhecimentos e capacidades [...]" (entrevistado 3) e "Quando surge algum problema, procuramos buscar na legislação, buscar num colega, sempre para responder dentro do que lei permite [...]" (entrevistado 4). Ao manifestarem-se sobre a execução dos serviços, os servidores explanaram: "[...] máximo de certeza sempre amparados pela legislação [...]" (entrevistado 1), "O nosso setor se baseia principalmente na padronização, no esforço em equipe em eficiência e responsabilidade [...]" (entrevistado 3) e "[...] os servidores do setor são muito responsáveis, nós temos uma equipe muito boa..." (entrevistado 4).

Os quatro servidores entrevistados possuem o mesmo posicionamento referente às quatro variáveis perguntadas. Entendem que existe um esforço conjunto dos colegas do setor para solucionar problemas e atender os questionamentos recebidos dos demais setores, além de enfatizarem que existem processos padronizados no setor, o que facilita o fluxo de trabalho, e que os procedimentos são realizados sempre embasados na legislação.

A dimensão "presteza" está relacionada ao setor assumir como seu determinado serviço ou problema a ser resolvido; trata-se do cuidado e da disponibilidade do servidor para ajudar um cliente ou colega de outro setor. Nessa dimensão, foram verificadas três variáveis. Ao serem perguntados sobre a informação e o cumprimento dos prazos, os entrevistados mencionaram: "[...] mesmo com falta de servidores e o excesso de trabalho, nós procuramos sempre cumprir e atender aos prazos" (entrevistado 1), "Eu acho que o setor atende 99,9\% das situações dentro dos prazos [...]" (entrevistado 2) e "[...] temos um formulário on-line para o atendimento de solicitações e informações que é respondido com a máxima brevidade possível [...]" (entrevistado 3). No que diz respeito ao atendimento das demandas, os respondentes afirmaram: "[...] nos organizamos por meio de sistemas e métodos para que o setor atenda todas as demandas" (entrevistado 2), "Acredito que as demandas sempre são atendidas, sempre com a máxima agilidade [...]" (entrevistado 3 ) e "O setor em geral é bem comprometido com atendimento" (entrevistado 1). Sobre o tópico disponibilidade dos servidores, estes declararam "Sempre tem bastante disponibilidade, o problema é que hoje estamos prejudicados porque saíram alguns servidores e não foram repostos [...]" (entrevistado 4), "Embora tenha um fluxo bem grande de trabalho, procuramos nos manter disponíveis para essas demandas" (entrevistado 2) e "estamos com poucos servidores e muito trabalho... mas nós nos desdobramos para dar retorno às demandas do setor" (entrevistado 1).

No que diz respeito a essa dimensão, também foi observado o mesmo entendimento dos entrevistados quanto às variáveis pesquisadas. Estes 
deixaram claro que há interesse em solucionar as demandas e que procuram atendê-las com a maior celeridade possível; entretanto, concordam que o volume de trabalho é grande, pois alguns servidores do setor foram transferidos, e as vagas não foram repostas.

A terceira dimensão avaliada foi a "segurança", que aborda o conhecimento e a habilidade dos servidores na prestação dos serviços de forma que gere confiança (segurança) aos demais. Nesse sentido, foram investigadas quatro variáveis. Com relação aos comportamentos do setor que podem gerar segurança, obtiveram-se os seguintes relatos: "[...] repassamos as informações e prestamos os serviços sempre amparados e com o respaldo da lei e, na medida do possível, os servidores fazem cursos de capacitação [...]" (entrevistado 1), "Padronização dos procedimentos, atenção à legalidade dos atos e transparência no trabalho executado" (entrevistado 3) e "[...] efetuar os procedimentos de forma correta, prestar as informações de maneira clara demonstra confiança para o pessoal que utiliza nosso setor" (entrevistado 2).

Já no que concerne aos procedimentos que demonstram segurança, foram feitas as seguintes observações: "Tudo que é liquidado e pago fica disponível no Portal da Transparência do governo federal; além disso, há um fluxograma e um manual em que todas as ações do setor são baseadas" (entrevistado 3), "Sendo cordial, tendo a informação. Quando não temos a informação, procuramos sempre buscar com um colega e sempre buscamos cursos de capacitação [...]" (entrevistado 2) e "Com informações corretas e baseada na legalidade" (entrevistado 4).

No tocante ao tratamento aos demais servidores, os respondentes informaram: "[...] procuramos sempre ser educados e ter um bom relacionamento com todos os demais servidores." (entrevistado 2), "Acredito que todos sejam atenciosos e cordiais, sempre tentamos tratar todos com respeito" (entrevistado 3) e "Buscamos sempre atender os colegas de forma clara, com educação [...]" (entrevistado 4). Com relação ao conhecimento dos servidores do setor, os entrevistados relataram: "[...] sempre procuramos aprimorar nossos conhecimentos" (entrevistado 2), "Todos têm o conhecimento necessário para desenvolver suas atividades com segurança" (entrevistado 3) e "Como trabalhamos num setor muito baseado na legislação, todos estão sempre lendo, se atualizando, pois as mudanças são constantes" (entrevistado 4).

Fica evidenciado, mais uma vez, que os servidores entrevistados compartilham da mesma opinião no tocante às variáveis de segurança. Podese verificar nos relatos expostos que a legalidade dos atos, os processos padronizados, o fato de que cada servidor tem suas funções definidas de forma clara, a busca constante por cursos de capacitação, a educação e o respeito são pontos cruciais para que o setor estabeleça segurança aos demais servidores.

A quarta e última dimensão investigada foi a "empatia", que trata da capacidade do servidor de compreender a necessidade do colega tomador do serviço, imaginando-se na mesma situação, e, ainda, da atenção pessoal 
AVALIAÇ̃̃O DA QUALIDADE DOS SERVIÇOS DO SETOR FINANCEIRO DE UMA UNIVERSIDADE: UMA ANÁLISE COMPARATIVA ENTRE A VISÃO DOS SERVIDORES PRESTADORES E DOS SERVIDORES USUÁRIOS DOS SERVIÇOS

dispensada a este colega. Dentro dessa perspectiva, foram examinadas quatro variáveis. Destacam-se, a seguir, alguns trechos mencionados pelos entrevistados com relação à atenção aos demais servidores: "Eu vejo todos sendo tratados sempre com muita atenção, o servidor se preocupa muito em tratar todos com cordialidade e com respeito" (entrevistado 3), "[...] a gente procura sempre resolver os problemas dos servidores [...]" (entrevistado 2) e "A maioria das vezes são sempre muito atenciosos e procuram responder da melhor forma possível a qualquer servidor ou colega que nos procuram" (Entrevistado 4)

No que se refere ao horário de atendimento, apareceram as seguintes falas: "Penso que poderia ser ampliado, para podermos ter mais contato e atendimento aos outros campi que funcionam em horários noturnos" (entrevistado 1), “[...] acredito que o horário é suficiente para atender a maioria das demandas, porém penso que seria interessante ampliar um pouco o horário para atender as necessidades dos campi que têm atividades noturnas" (entrevistado 3) e "[...] Nós atendemos dentro desse horário da melhor maneira possível, mas eu penso que poderia ser estendido um pouco mais, pois a Universidade tem dez campi, os quais ficam descobertos fora desse horário" (entrevistado 4). Com relação ao interesse dos servidores do setor em solucionar problemas, os respondentes expuseram: "[...] sempre procuramos solucionar os problemas com celeridade" (entrevistado 3), "Buscamos atender os interesses de todos os setores dentro das possibilidades, atendemos da melhor maneira possível" (entrevistado 4) e "São todos interessados em resolver da melhor maneira possível" (entrevistado 2).

No que diz respeito à compreensão dos servidores do setor com as necessidades específicas dos demais servidores, os entrevistados retrataram: "Nós respeitamos as necessidades e procuramos sempre quando possível ajudar no que estiver em nosso alcance" (entrevistado 1), "[...] Sempre procuramos ter compreensão da realidade dos outros setores e das demandas [...]" (entrevistado 2) e "Sempre procuramos buscar compreender as particularidades de cada setor..." (entrevistado 4).

No que concerne à dimensão "empatia", os entrevistados novamente apresentaram o mesmo ponto de vista com relação às variáveis analisadas. Demonstraram preocupação em atender de forma individualizada, respeitando as especificidades dos outros setores e dos usuários.

\subsection{Análise da pesquisa com servidores usuários dos serviços}

Antes de proceder à avaliação dos serviços prestados, é necessário conhecer a amostra pesquisada, composta de 140 servidores (docentes e técnicos-administrativos) lotados nos 10 campi e na Reitoria da UNIPAMPA. Para isso, as variáveis, tanto profissionais quanto sociodemográficas foram distribuídas em gráficos e apresentadas na sequência. 
4.2.1 Análise do perfil dos respondentes

Em relação ao gênero dos respondentes, existe uma pequena maioria do sexo masculino, com $52,1 \%(n=72)$ da amostra pesquisada. O gênero feminino aparece na pesquisa com 47,9\% ( $n=67)$, conforme pode ser visualizado no Gráfico 1.

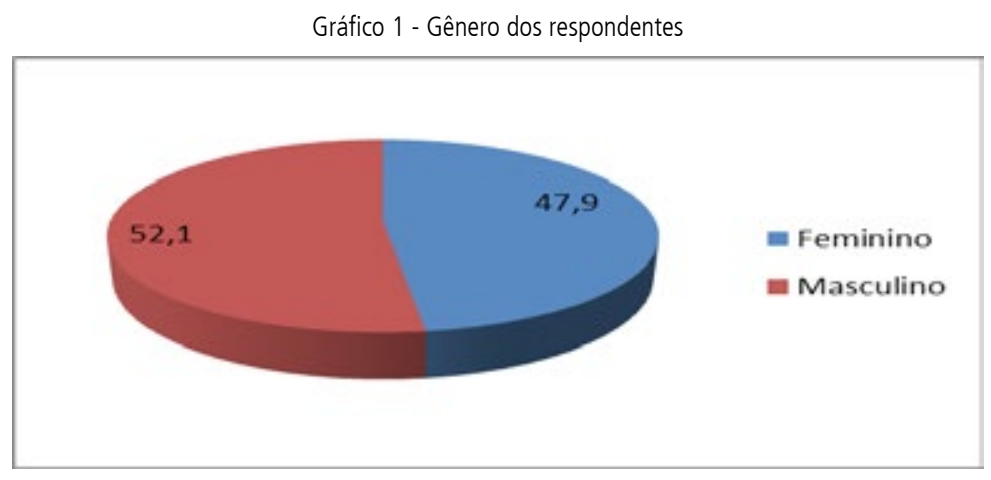

Fonte: elaborado pelos autores

No que se refere à categoria dos respondentes, há um discrepância na amostra pelo fato de que $68,6 \%(n=96)$ dos respondentes são técnicosadministrativos, e apenas $31,4 \%(n=44)$ são docentes (Gráfico 2$)$.

Gráfico 2 - Categoria dos respondentes

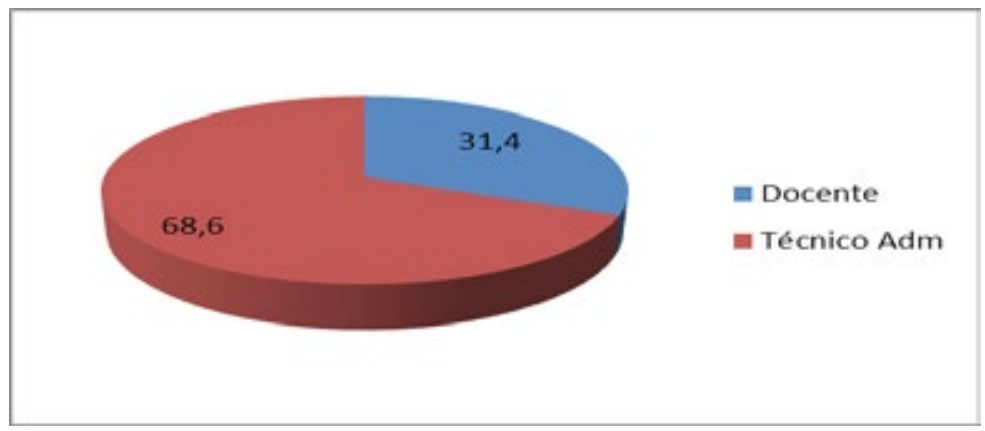

Fonte: elaborado pelos autores

Sobre a lotação dos respondentes, percebe-se, no Gráfico 4, a predominância de servidores lotados na Reitoria; porém, todas as unidades possuem servidores que responderam a pesquisa. 
AVALIAÇÃO DA QUALIDADE DOS SERVIÇOS DO SETOR FINANCEIRO DE UMA UNIVERSIDADE: UMA ANÁLISE COMPARATIVA ENTRE A VISÃO DOS SERVIDORES PRESTADORES E DOS SERVIDORES USUÁRIOS DOS SERVIÇOS

Gráfico 3 - Lotação dos respondentes

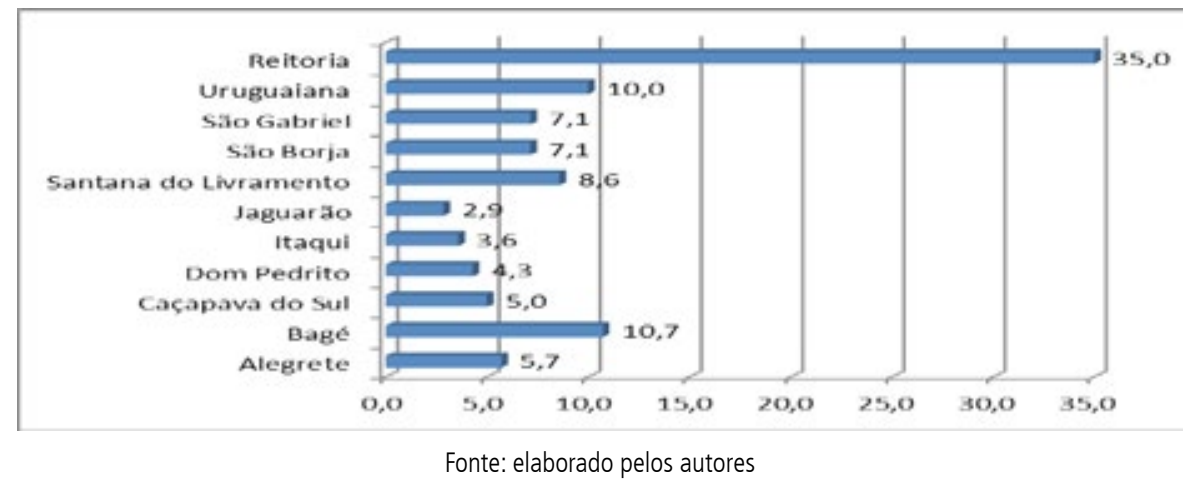

Em relação ao tempo de serviço dos respondentes, o Gráfico 4 demonstra que há um maior número de respondentes que trabalha na UNIPAMPA de um a três anos, 38,6\% ( $n=54)$, seguido de um empate entre os que trabalham de cinco a sete anos e os que estão há mais de mais anos na Instituição, ambos com $22,9 \%(n=32)$. Posteriormente, estão os que trabalham de três a cinco anos, $10,7 \%(n=15)$, e os trabalhadores com até um ano de serviço, $5 \%(n=7)$.

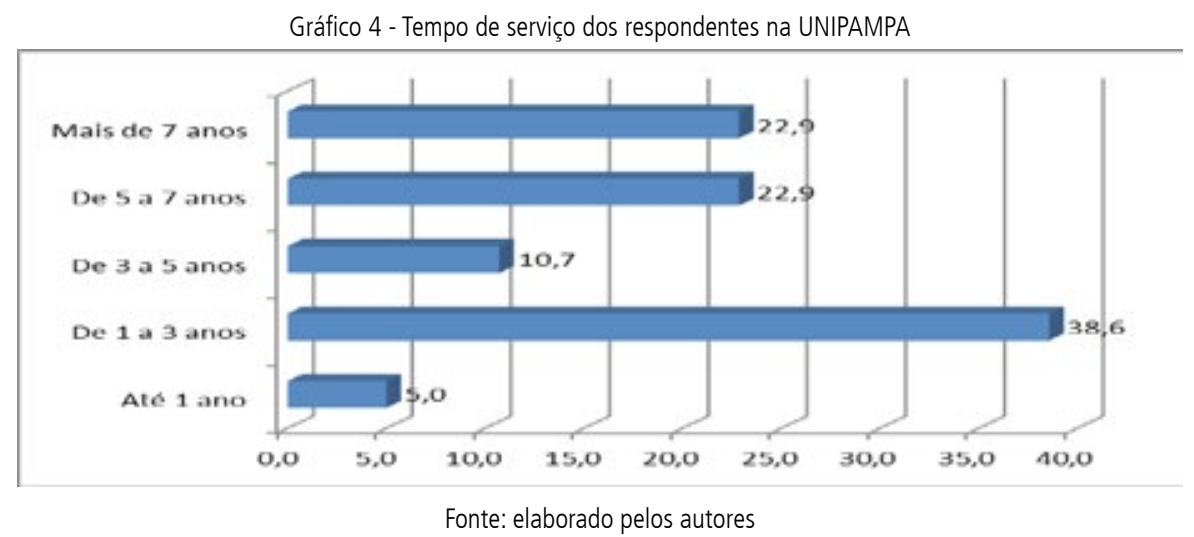

\subsubsection{Análise descritiva}

Assim como na entrevista, para a análise das médias, dividiram-se as variáveis de avaliação da qualidade em quatro grupos, de acordo com as dimensões do modelo. Desse modo, nos quadros a seguir, apresentaram-se as médias por dimensão em ordem crescente conforme a escala utilizada no instrumento de pesquisa.

As cinco variáveis apresentadas no Quadro 1 obtiveram médias entre 3,99 e 4,23, perfazendo uma média geral da dimensão "confiabilidade" de 4,06 , o que, de acordo com a escala, representa uma avaliação que varia de boa a ótima, e um desvio-padrão entre 0,947 e 1,135, indicando baixa disparidade nas respostas. 
Quadro 1 - Avaliação da dimensão "confiabilidade"

\begin{tabular}{|c|l|c|c|}
\hline \multicolumn{1}{|c|}{ CONFIABILIDADE } & Média & $\boldsymbol{\sigma}$ \\
\hline C4 & $\begin{array}{l}\text { O setor financeiro da instituição onde você trabalha cumpre os prazos para } \\
\text { prestar as informações e/ou serviços que lhe são solicitados }\end{array}$ & 3,99 & 1,103 \\
\hline C2 & $\begin{array}{l}\text { Quando você tem algum problema relativo aos serviços prestados no setor, } \\
\text { o setor financeiro da instituição onde você trabalha demonstra o sincero } \\
\text { interesse em resolvê-lo }\end{array}$ & 4,01 & 1,135 \\
\hline C1 & $\begin{array}{l}\text { Quando o setor financeiro da instituição onde você trabalha promete fazer } \\
\text { um serviço em determinado tempo, ele o faz }\end{array}$ & 4,02 & 1,042 \\
\hline C5 & $\begin{array}{l}\text { O setor financeiro da instituição onde você trabalha enfatiza a forma correta } \\
\text { de efetuar os procedimentos e registos }\end{array}$ & 4,07 & 1,036 \\
\hline C3 & $\begin{array}{l}\text { O setor financeiro da instituição onde você trabalha executa corretamente os } \\
\text { serviços que lhe são solicitados }\end{array}$ & 4,23 & 0,947 \\
\hline \multicolumn{2}{|c|}{ Média da dimensão "confiabilidade" } & $\mathbf{4 , 0 6}$ & $\mathbf{0 , 9 2 6}$ \\
\hline
\end{tabular}

Fonte: elaborado pelos autores

De acordo com o Quadro 2, pode-se verificar que a dimensão "presteza" obteve a menor média $(x=3,82)$ entre as quatro dimensões analisadas. As médias ficaram entre 3,61 e 3,98, correspondendo a uma avaliação de regular a boa. O desvio-padrão permaneceu entre 1,104 e 1,185, demonstrando que houve pouca discordância entre os respondentes. Observou-se, ainda, que a variável (P9) apresentou a menor média $(x=3,61)$ e que a variável $(P 6)$ espelhou a segunda pior média $(x=3,76)$ dentre as 18 variáveis retratadas na pesquisa.

Quadro 2 - Avaliação da dimensão "presteza"

\begin{tabular}{|c|l|c|c|}
\hline \multicolumn{1}{|c|}{ PRESTEZA } & Média & $\boldsymbol{\sigma}$ \\
\hline P9 & $\begin{array}{l}\text { Os servidores do setor financeiro da instituição onde você trabalha } \\
\text { estão sempre disponíveis (nunca estão muito ocupados) para atender } \\
\text { aos seus pedidos de informações ou serviços }\end{array}$ & 3,61 & 1,173 \\
\hline P6 & $\begin{array}{l}\text { Os servidores do setor financeiro da instituição onde você trabalha } \\
\text { informam exatamente quando as solicitações ou os serviços serão } \\
\text { prestados }\end{array}$ & 3,76 & 1,185 \\
\hline P7 & $\begin{array}{l}\text { Os servidores do setor financeiro da instituição onde você trabalha } \\
\text { atendem prontamente as demandas de informações e serviços }\end{array}$ & 3,93 & 1,104 \\
\hline P8 & $\begin{array}{l}\text { Os servidores do setor financeiro da instituição onde você trabalha } \\
\text { estão sempre dispostos a ajudá-lo }\end{array}$ & 3,98 & 1,172 \\
\hline & Média da dimensão "presteza" & $\mathbf{3 , 8 2}$ & $\mathbf{1 , 0 0 9}$ \\
\hline
\end{tabular}

Fonte: elaborado pelos autores

A dimensão "segurança" (Quadro 3) apontou a melhor avaliação por variável - $S 12(x=4,27)$ - e por dimensão, refletindo uma média geral de 4,14 e caracterizando uma avaliação entre boa e ótima. As médias figuraram entre 4,01 e 4,27, retratando média acima de 4,00 para todas as variáveis constantes na dimensão. O desvio-padrão foi o menor das quatro dimensões, ficando entre 0,872 e 1,063 e configurando a menor discrepância entre os respondentes. 
AVALIAÇÃO DA QUALIDADE DOS SERVIÇOS DO SETOR FINANCEIRO DE UMA UNIVERSIDADE: UMA ANÁLISE COMPARATIVA ENTRE A VISÃO DOS SERVIDORES PRESTADORES E DOS SERVIDORES USUÁRIOS DOS SERVIÇOS

Quadro 3 - Avaliação da dimensão "segurança"

\begin{tabular}{|c|l|c|c|}
\hline \multicolumn{2}{|c|}{ SEGURANÇA } & Média & $\boldsymbol{\sigma}$ \\
\hline S10 & $\begin{array}{l}\text { O comportamento dos servidores do setor financeiro da instituição } \\
\text { onde você trabalha gera confiança em você com relação às } \\
\text { informações prestadas e/ou aos serviços realizados }\end{array}$ & 4,01 & 1,063 \\
\hline S13 & $\begin{array}{l}\text { Os servidores do setor financeiro da instituição onde você trabalha } \\
\text { têm conhecimento para responder às suas dúvidas a respeito dos } \\
\text { serviços prestados pelo setor }\end{array}$ & 4,13 & 0,872 \\
\hline S11 & $\begin{array}{l}\text { Você se sente seguro ao solicitar informações ou serviços aos } \\
\text { servidores do setor financeiro da instituição onde trabalha }\end{array}$ & 4,15 & 0,974 \\
\hline S12 & $\begin{array}{l}\text { Os servidores do setor financeiro da instituição onde você trabalha } \\
\text { são sempre educados com você }\end{array}$ & 4,27 & 0,936 \\
\hline \multicolumn{2}{|c|}{ Média da dimensão "segurança" } & $\mathbf{4 , 1 4}$ & $\mathbf{0 , 8 3 4}$ \\
\hline
\end{tabular}

Fonte: elaborado pelos autores

No que diz respeito à dimensão "empatia" (Quadro 4), as médias ficaram entre 3,81 e 4,04, e a média geral da dimensão foi de 3,92, segunda menor média entre as quatro dimensões, perfazendo uma avaliação entre regular e boa. Notou-se, também, que as variáveis E18, E14 e E16 apresentaram, respectivamente, a terceira, a quarta e a quinta menores médias dentre as 18 variáveis analisadas no estudo. 0 desvio-padrão variou entre 1,028 e 1,154, 0 que denota regularidade nas respostas obtidas.

Quadro 4 - Avaliação da dimensão "empatia"

\begin{tabular}{|l|l|c|c|}
\hline \multicolumn{2}{|c|}{ EMPATIA } & Média & $\boldsymbol{\sigma}$ \\
\hline E18 & $\begin{array}{l}\text { Os servidores do setor financeiro da instituicão onde você trabalha } \\
\text { compreendem as necessidades espećfícas do público interno }\end{array}$ & 3,81 & 1,057 \\
\hline E14 & $\begin{array}{l}\text { O setor financeiro da instituição onde você trabalha oferece atenção } \\
\text { individual a você }\end{array}$ & 3,86 & 1,154 \\
\hline E16 & $\begin{array}{l}\text { Os servidores do setor financeiro da instituição onde você trabalha dão } \\
\text { atenção pessoal a você }\end{array}$ & 3,89 & 1,057 \\
\hline E15 & $\begin{array}{l}\text { O horário de funcionamento do setor financeiro é conveniente para atender } \\
\text { as demandas dos demais servidores da instituição }\end{array}$ & 4,03 & 1,066 \\
\hline E17 & $\begin{array}{l}\text { Os servidores do setor financeiro da instituição onde você trabalha } \\
\text { demonstram interesse em solucionar suas demandas e/ou seus problemas }\end{array}$ & 4,04 & 1,028 \\
\hline \multicolumn{2}{|c|}{ Média da dimensão "empatia" } & $\mathbf{3 , 9 2}$ & $\mathbf{0 , 9 0 9}$ \\
\hline
\end{tabular}

\section{Considerações finais}

Ao analisarmos a dimensão "confiabilidade", que se refere à habilidade da empresa em prestar o serviço corretamente e dentro do prazo acordado, percebeu-se que os servidores entrevistados possuem o mesmo posicionamento. Estes entendem que existe um esforço conjunto dos colegas do setor para solucionar problemas e atender os questionamentos recebidos dos demais setores. As médias apresentadas na avaliação descritiva vêm ao encontro desse entendimento, pois a dimensão obteve a segunda melhor média, sendo avaliada entre boa e ótima na percepção dos servidores usuários. 
Com relação à dimensão "presteza", foram analisados itens que representam a disponibilidade e o interesse dos servidores em atender os usuários. Foi observado o mesmo entendimento dos entrevistados no que se refere às variáveis pesquisadas: os entrevistados ressaltam que há interesse em solucionar as demandas e que procuram atendê-las com a maior celeridade possível, concordando, entretanto, que o volume de trabalho é grande. Verificou-se que, nessa dimensão, foram refletidas as menores médias sob a ótica dos usuários dos serviços, o que gera uma discordância entre o pensamento dos servidores do setor e dos usuários dos serviços. Porém, essa dissonância pode ser explicada pelo grande volume de trabalho relatado pelos servidores entrevistados. Vale ressaltar, ainda, que, embora tenha apresentado a menor média, nenhuma das variáveis foi avaliada como ruim, permanecendo a avaliação entre regular e boa.

Quanto à dimensão "segurança", verificou-se que o setor é organizado e regrado, o que, no entendimento dos entrevistados, facilita o trabalho e permite que seja feito com segurança e embasamento legal. Essa visão é reafirmada pelo resultado da pesquisa com os usuários dos serviços, em que a dimensão obteve a maior média entre as quatro dimensões analisadas, retratando uma avaliação entre boa e ótima.

No que diz respeito à dimensão "empatia", observou-se que os servidores do setor acreditam que prestam atendimentos respeitando as especificidades de cada usuário e/ou setor. Porém, a média geral dessa dimensão na percepção dos servidores usuários variou entre regular e boa, o que demonstra um contraponto entre a percepção dos servidores do setor financeiro e a visão dos servidores usuários dos serviços.

Os resultados desta pesquisa foram repassados ao responsável pelo setor financeiro da instituição, com a finalidade de servir de suporte para melhorias que possam vir a serem implementadas. Para fins acadêmicos, há, ainda, a possibilidade de novas pesquisas em outros setores da Universidade, bem como de uma nova pesquisa no setor com objetivo de estabelecer comparações com este estudo.

\section{Referências}

ALBRECHT, Karl. Revolução nos serviços. São Paulo: Pioneira, 1992.

ARAÚJO, Alcides Carlos. CHAMIE, Beatriz Cavalcante. NASCIMENTO, Camila Leoni. MARINHO, Bernadete de Lourdes. Qualidade de serviços em restaurantes finos na cidade de São Paulo. 2010.

ANDRADE, Maria Margarida de. Introdução à Metodologia do Trabalho científico. $7^{a}$ ed., São Paulo: Atlas, 2005.

BARDIN, L. Análise de Conteúdo. 5. ed. Lisboa: Edições 70, 2009.

BATESON, John; HOFFMAN, Douglas. Marketing de Serviços. Porto Alegre: Bookman, 2001

CAMPOS, Claudinei José Gomes. MÉTODO DE ANÁLISE DE CONTEÚDO: ferramenta para a análise de dados qualitativos no campo da saúde. Rev Bras Enferm, Brasília (DF) 2004 set/out;57(5):611-4 
AVALIAÇ̃̃O DA QUALIDADE DOS SERVIÇOS DO SETOR FINANCEIRO DE UMA UNIVERSIDADE: UMA ANÁLISE

COMPARATIVA ENTRE A VISÃO DOS SERVIDORES PRESTADORES E DOS SERVIDORES USUÁRIOS DOS SERVIÇOS

CORRÊA, Kenneth. Fatores determinantes da qualidade em serviços. 2000. Disponível em: <http:// administracaoegestao.com.br/marketing-internacional/fatores-determinantes-da-qualidade-em-servicos/> Acesso em: 09 ago 2016. 00:35

COSTA, Júlio César Mourão. Qualidade de Atendimento na percepção do cliente: aplicação do modelo SERVQUAL no varejo farmacêutico. Belo Horizonte. 2009.

COUTINHO, Fernanda Gabriela de Andrade. MISUNAGA, Haroldo Yutaka. Marketing de Serviços - o Caso de uma Rede de Franquias de Pastel em Maringá-PR. 2011. Disponível em: <http://www.intercom.org.br/ papers/regionais/sul2011/resumos/R25-1012-1.pdf> Acesso em: 08 ago 2016, 22:15.

FREITAS, André Luís Policani. A qualidade em serviços no contexto da competitividade. Revista Produção. ISSN 1676 - 1901 / Vol. 5/ Num. 1/ Março de 2005.

GIL, Antonio Carlos. Métodos e Técnicas de Pesquisa Social. 6a ed., São Paulo: Atlas, 2012.

GRÖNROOS, C. Marketing: gerenciamento e serviços. Tradução Arlete Simille Marques. 2. ed. Rio de Janeiro: Campus/Elsevier, 2003.

GUPTA, S.; KIM, H. W.; Value-Driven Internet Shopping: The Mental Accounting Theory Perpective. Psychology \& Marketing, v. 27, n. 1, p. 13-35, 2010.

KOTLER, Philip. Administração de Marketing, 10 ed. São Paulo, Editora Prentice Hall. 2000

LEJEUNE, M. Un regard d'ensemble sur le marketing des services. Revue Française du Marketing, v. 121, n. 1, p. 9-27, 1989.

LAS CASAS, A. L. Qualidade total em serviços: conceitos, exercícios e casos práticos. 3. ed. São Paulo: Atlas, 1999. 206 p.

LUIZ, João. Qualidade em serviços. 2014. Disponível em: <http://www.administradores.com.br/artigos/negocios/ qualidade-em-servicos/81805/> Acesso em 09 ago 2016.

OLIVEIRA, Edson Gomes. MARCONDES, Kleiton dos Santos. MARELE, Ernesto Pedro. GALVÃO, Henrique Martins. Marketing de serviços: relacionamento com o cliente e estratégias para a fidelização. 2009. Disponível em: <http://www.publicacoes.fatea.br/index.php/raf/article/viewFile/219/176> Acesso em 08 ago 2016, 22h.

PARASURAM, Alternative Scales for Measuring Service Quality: A Comparative Assessment Based on Psychometric and Diagnostic Criteria. Journal of Retailing, Volume 70, Number 3, pp. 201-230, ISSN 0022-4359. Copyright, 1994, by New York University.

MACHADO, Melise Dantas. QUEIROZ, Timóteo Ramos. MARTINS, Manoel Fernando. Mensuração da qualidade de serviço em empresas de fast food. Disponível em: <http://www.scielo.br/scielo.php?script=sci_ arttext\&pid=S0104-530X2006000200008 > Acesso em: 09 ago 2016, 00:45

MOTA, Mariângela Gonçalves. Conceitos e Práticas de Marketing: um estudo da sua adoção por empresas prestadoras de serviços de saúde em Montes Claros/MG. Disponível em: <http://www.fpl.edu.br/2013/ media/pdfs/mestrado/dissertacoes_2009/dissertacao_mariangela_goncalves_mota_2009.pdf>Acesso em: 08 ago 2016, 21h

MOURA, Luiz Rodrigo Cunha. SALDANHA, Luiz Cláudio Lagoeiro. VEIGA, Ricardo Teixeira. MOURA, Luiz Eduardo Leite. CUNHA, Nina Rosa Silveira. Avaliação da Qualidade de Serviços Utilizando a Escala Servqual: o Estudo de Caso Matermed. Disponível em: <http://revistas.una.br/index.php/reuna/article/ viewFile/255/231> Acesso em: 09 ago 2016, 00:50

NASCIMENTO, Isidro José Bezerra Maciel Fortaleza. O marketing de serviços nas pequenas e médias empresas: uma abordagem teórica e reflexiva. Revista Inovação. 2012.

PARASURAM, Alternative Scales for Measuring Service Quality: A Comparative Assessment Based on Psychometric and Diagnostic Criteria. Journal of Retailing, Volume 70, Number 3, pp. 201-230, ISSN 0022-4359. Copyright, 1994, by New York University.

RUA, Maria das Graças. Políticas Públicas. Módulo Básico. Especialização em Gestão Pública. PNAP. CAPES. 2012.

SALOMI, et al. Servqual x Servperf: comparação entre instrumentos para Avaliação da Qualidade de Serviços Internos, Gestão e Produção, São Paulo, v.12, n.2, p.279-293, mai.-ago. 2005 
SEVERINO, Antônio Joaquim. Metodologia do Trabalho científico. $23^{a}$ ed., São Paulo: Cortez, 2007.

SOARES, Fabrício. Serviços 5 estrelas: Uma introdução à qualidade nos serviços. $2^{\mathrm{a}} \mathrm{Ed}$. Rio de Janeiro: Editora Qualitymar, 1994

TONTINI, G.; SANT'ANA, A.J. Interação de atributos atrativos e obrigatórios de um serviço na satisfação do cliente. Revista Produção, São Paulo, v. 18, n. 1, p. 112125, jan./abr. 2008.

UNIPAMPA. Reitoria. Coordenadoria de Contabilidade e Finanças. Disponível em: <http://porteiras.r.unipampa.edu.br/portais/ccf/equipe/> Acesso em: 05 jun. 2016. 